\section{Analysis highlights suicide risk of antidepressants}

Erika Check, Washington

The potential link between antidepressants and suicidal behaviour in children has been given further substance by a study from the US Food and Drug Administration (FDA).

Children and adolescents on antidepressants called selective serotonin reuptake inhibitors are 1.8 times more likely to experience suicidal thoughts or behaviour than those who do not take the drugs, the FDA said on 20 August. The analysis, by Tarek Hammad, an FDA safety reviewer, rests on drug-company data from 25 clinical trials.

The study confirms earlier findings by Andrew Mosholder, an epidemiologist at the FDA, who produced an analysis of the data in February but was banned from presenting his results in public. The FDA said at the time that the findings were only preliminary, but news of the suppression fuelled fears that data on the drugs were being withheld by drug companies and government regulators.

Mosholder's analysis put the risk only slightly higher, at 1.9 times greater for children on the drugs. But unlike that study, Hammad's analysis did not find a significantly higher risk for the subgroup of children with serious depression.

The risk also varied for the nine drugs studied. Fluoxetine, marketed as Prozac, did not increase the risk of suicide. Others, such as venlafaxine (Effexor), were linked to a significantly higher risk of self-harming thoughts and behaviour.

The analysis increases the pressure on the FDA to further discourage doctors from using the drugs 'off-label' - prescribing them in cases for which they are not approved. Of the nine drugs in the study, only fluoxetine is specifically approved to treat childhood depression. The FDA has already asked makers of the drugs to use labels warning that adults and children on the medication must be monitored for suicidal behaviour, but two advisory committees will meet next month to discuss whether more should be done.

The data used in the study are largely unpublished, leading to renewed calls for the government to require drug makers to release results from clinical trials. "Mosholder's initial findings have been confirmed and reconfirmed," says Senator Chuck Grassley (Republican, Iowa). "When there are known risks with a drug, the information must be made available in a timely way."

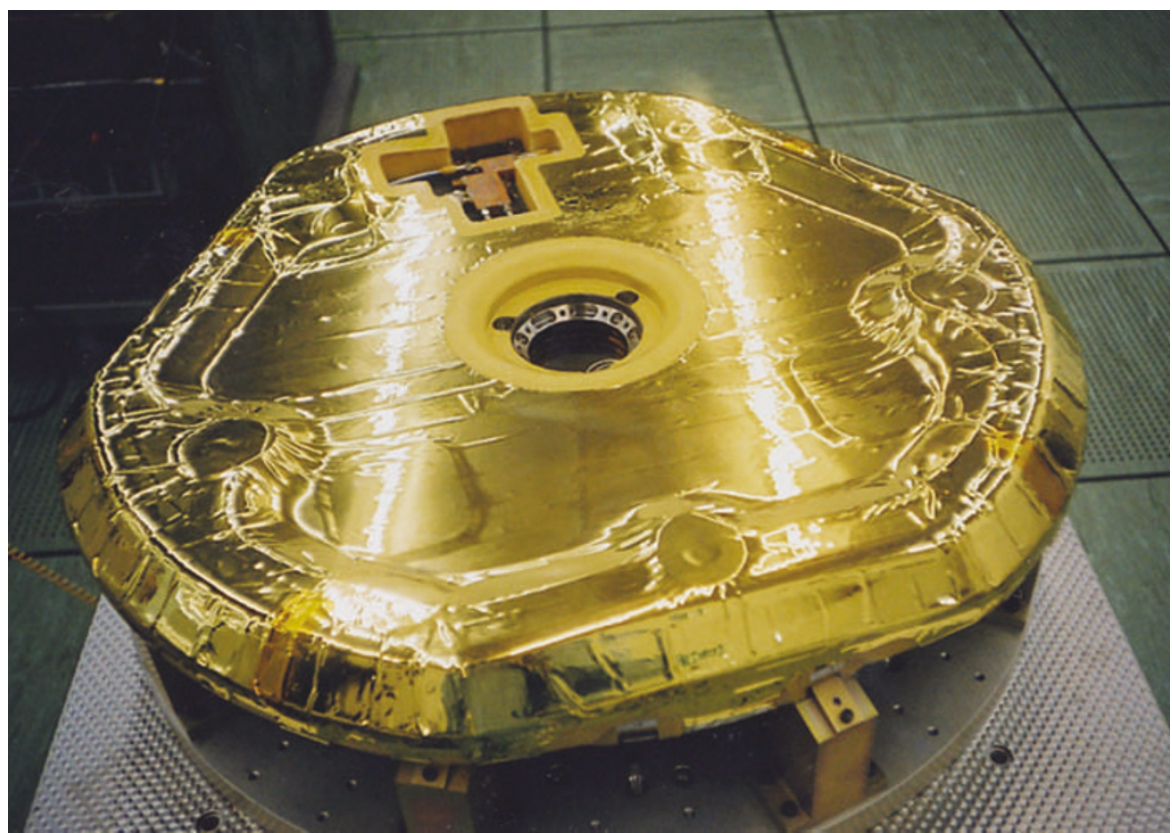

Missing in action: the Beagle 2 martian lander was dogged by money problems.

\title{
Beagle team hounds space agency over lost lander
}

\section{Mark Peplow, London}

The team behind the ill-fated Beagle 2 Mars lander has hit back at its critics in the European Space Agency (ESA).

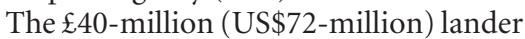
was last seen leaving ESA's Mars Express spacecraft for the surface of Mars on 19 December last year, since when little information has emerged about why it went missing. A largely confidential ESA report, issued in May, included a list of criticisms of design choices made by the lander team — but now the Beagle researchers have had their say.

The team's report into what went wrong, released on 24 August, says that ESA regarded Beagle as nothing more than an instrument on board its Mars Express craft. The programme "was consistently forced to meet the needs of Mars Express at the expense of its own requirements", write mission manager Mark Sims of the University of Leicester and his colleagues.

The report also dismisses accusations by some engineers that Beagle's airbags, which were meant to cushion its impact on the martian surface, were not properly tested. The team points out that the airbags were made by the company behind a similar system used on NASA's exploration rovers, which arrived safely on Mars this January.

The Beagle researchers say they could have learned more about what went wrong had they not been prevented from installing a communication device that would have operated after the lander left Mars Express and before it touched down on the planet. They had designed such a system, but the report says they were advised by ESA that no Earth or space-based receiver would be available to relay the messages.

One possible clue to the mission's failure, says the report, comes from readings from Mars Express, which show that the martian atmosphere was thinner than expected at the point at which Beagle was released. That means Beagle's descent would not have been slowed as much as calculated. Sims and his team say that this problem could not have been foreseen, and add that a better understanding of the martian atmosphere is crucial to the success of any future missions.

Despite the antagonistic tone taken towards ESA, the Beagle team agrees with the agency on several points. Both parties say that any future orbiter-and-lander mission should be managed as a single programme. Sims and his colleagues also acknowledge that Beagle suffered from a lack of money early in the project: just 20 months before the lander was to be attached to Mars Express, $80 \%$ of the craft remained unfinished, the report admits.

ESA officials had only just seen the report as Nature went to press, but they say that it will be of great use to future Mars lander teams. "I feel glad that they have not homed in on a single failure mode," says David Southwood, director of science at the agency. The fact that no single fault has been focused on "has forced an in-depth analysis of everything”. 